\title{
ISLAM DAN PENDIDIKAN: STUDI PEMIKIRAN MOHAMMAD HATTA
}

\author{
Ahmad Syauqi Fuady \\ STIT Muhammadiyah Bojonegoro \\ Email: syauqi.asf68@gmail.com
}

\begin{abstract}
This paper is a literature study using a historical approach that takes primary and secondary data from the writings of Mohammad Hatta, autobiography, and writing about Mohammad Hatta. Hatta was one of the important figures for the birth of the Republic of Indonesia who participated in the independence struggle. Hatta is also known as a thinker whose broad spectrum includes economics, philosophy, ideology, politics, social, culture, religion, and education. Religion became an integral part of Hatta since childhood. Islam for Hatta became the basis of personal values that guide behavior. Likewise, religion has a role in developing social, political, and social life. Hatta's Islamic thought style was more substantially patterned, rather than formative. Education was also an identical part of Hatta since the struggle for Indonesian independence. The political task in the main colony is to educate the people to understand their duties, rights, and responsibilities so that new cadres of leaders can be born. After Indonesia's independence, the issue of education became one of the concerns of Hatta. Education for an independent country is an investment in the future of a country.
\end{abstract}

Keywords: Mohammad Hatta, Thought, Islam, Education.

\section{PENDAHULUAN}

Agama dan kehidupan relijius juga sangat lekat dengan Mohammad Hatta. Agama menjadi laku yang mengiringi kehidupan sehari-harinya. Testimoni orang-orang dekat, kawan seperjuangan, bahkan lawan politik Hatta mengakui perihal integritas dan moral pribadi Manusia Hatta. Ketaatan dalam menjalankan agama dipegang secara teguh dan utuh. Salat dan puasa tidak pernah luput dijalankan oleh Hatta. Saat menempuh pendidikan di Belanda, kawankawan sesama mahasiswa di Belanda mengutarakan bahwa Hatta selalu menunaikan salat, dan tidak pernah sekalipun main perempuan, keluar malam, dan menenggak minuman keras. Nilainilai Islam menjadi pondasi kata, sikap, dan lebih-lebih perilaku Mohammad Hatta. 
Selain menempuh pendidikan hingga mendapat sarjana ekonomi di Belanda, pendidikan agama diterima Hatta sejak kecil. Bahkan, kakek Hatta dari ayah Muhammad Djamil, Syaikh Abdul Rahman, adalah seorang ulama dan tokoh utama Tarikat Naqsyabandiyah. Surau milik Syaikh Abdul Rahman menjadi pusat pengajaran agama Islam di Minangkabau. Dari keluarga yang demikian inilah, Hatta memperoleh didikan tentang bagaimana harus hidup dan berperilaku secara aturan Islam. Perasaan keislaman telah tertanam dalam jiwa Hatta sejak kecil. ${ }^{1}$ Selain memperoleh pendidikan agama dari keluarga, Hatta juga belajar agama kepada dua tokoh ulama pembaharu di Minangkabau yakni Syaikh Muhamamd Djamil Djambek ${ }^{2}$ dan Haji Abdullah Ahmad². Dari ulama-ulama tersebut, Hatta memperoleh pengetahun dasar Islam dan kewajiban penggunaan akal dalam menuntut ilmu pengetahuan modern. Nilai-nilai modernisme Islam telah dikenal Hatta sejak kecil. Schulte Nordholt menilai pribadi Hatta sebagai perpaduan antara kesadaran agama dan tradisi Minangkabau dengan pemikiran modern. Modernisme Islam, bagi Hatta, adalah pilihan yang sewajarnya saja. ${ }^{4}$

Selain agama, pendidikan menjadi bagian penting dalam perjuangan Hatta. Orientasi perjuangan politik Mohammad Hatta adalah pendidikan. Oleh sebab itu, setelah kembali dari Belanda, Mohammad Hatta mendirikan partai yang berorientasi untuk mendidik kader pemimpin yakni Pendidikan Nasional Indonesia (PNI-Baru) untuk membedakan dengan Partai Nasional Indonesia (PNI) pimpinan Soekarno yang lebih berorientasi untuk meraih dukungan massa rakyat. Atas dasar itulah, Deliar Noer membedakan antara Soekarno dengan Mohammad Hatta, "Soekarno lebih suka menghadapi massa, Hatta lebih suka mendidiknya." Menulis dalam Daulat Rakyat, majalah resmi milik Pendidikan Nasional Indonesia (PNI-Baru), Mohammad Hatta menegaskan dasar pemikiran politiknya, "Sifat perkumpulan kita pendidikan, karena memang maksud kita mendidik diri kita. Politik di negeri jajahan terutama berarti pendidikan." 6

Setelah Indonesia merdeka, persoalan pendidikan tetap menjadi perhatian Mohammad Hatta. Orientasi terhadap modal sumber daya manusia (human capital) dengan pengutamaan

\footnotetext{
${ }^{1}$ Mohammad Hatta, Untuk Negeriku Sebuah Otobiografi Vol. 1: Bukittinggi-Rotterdam Lewat Betawi (Jakarta: Kompas, cetakan ketiga, September 2013), 73.

${ }^{2}$ Deliar Noer, Gerakan Moderen Islam di Indonesia 1900-1942 (Jakarta: LP3ES, cetakan kedua, 1982), $42-44$.

${ }^{3}$ Ibid, 46-47.

${ }^{4}$ Taufik Abdullah, "Kata Pengantar" dalam Deliar Noer, Mohammad Hatta Hati Nurani Bangsa, x.

${ }^{5}$ Deliar Noer, Mohammad Hatta Hati Nurani Bangsa (Jakarta: Kompas, 2012), 41.

6 Mohammad Hatta, "Pendidikan" dalam Mohammad Hatta, Kumpulan Karangan I (Jakarta: Penerbitan dan Balai Buku Indonesia, 1953), 116.
} 


\section{Ahmad Syauqi Fuady}

human investment lewat pendidikan artinya menempatkan manusia Indonesia sebagai substansi pokok dalam merebut masa depan bangsa. ${ }^{7}$ Pendidikan yang bermutu, baik dalam kualitas maupun dalam sebaran kuantitas adalah jaminan akan masa depan yang cerah bagi suatu bangsa. Pendidikan yang bermutu akan mampu meningkatkan kualitas nilai kesucian manusia sesuai fitrahnya yang dianugerahkan Tuhan sehingga degradasi moral dapat ditahan lajunya. Selain itu juga akan meningkatkan kemampuan berpikir dan bertindak rasional yang pada gilirannya akan berefek positif bagi peningkatan profesionalisme dan keahlian kerja. ${ }^{8}$

\section{ISLAM DAN KEHIDUPAN BERNEGARA MENURUT HATTA}

Sosok Mohammad Hatta senantiasa lekat dengan penghilangan tujuh kata "Ketuhanan dengan Kewajiban Menjalankan Syariat Islam bagi Pemeluk-pemeluknya" dari Piagam Jakarta. Mohammad Hatta dianggap sebagai biang keladi penghapusan tujuh kata tentang syariat Islam dalam Piagam Jakarta. ${ }^{9}$ Terhadap hal ini, Mohammad Hatta berargumen bahwa hilangnya semangat Piagam Jakarta tidaklah hilang dengan hilangnya Tujuh Kata tersebut. Setiap peraturan yang bersumber dari syariat Islam dapat diajukan oleh umat Islam yang duduk di lembaga legislatif untuk dijadikan peraturan perundang-undangan yang berlaku bagi umat Islam. "Dengan tjara begitu lambat laun terdapat bagi umat Islam Indonesia suatu sistim sjari' at Islam jang teratur dalam Undang-Undang, berdasarkan Qur'an Hadith, jang sesuai pula dengan keperluan masjarakat Islam sekarang." ${ }^{10}$ Corak keislaman Mohammad Hatta lebih bersifat substantif alih-alih bersifat formatif. ${ }^{11}$ Islam bagi Hatta, menurut Ahmad Syafi'i Ma'arif, hendaknya menjadi seperti garam yang tak tampak mencolok namun terasa. Bukan seperti gincu yang tampak mencolok tetapi hambar.

Dalam pembagian tipologi kepemimpinan nasional, Mohammad Hatta bersama Soekarno, Sjahrir, Soepomo dan lainnya ditempatkan ke dalam tipologi "kelompok nasionalis", yang berseberangan dengan "kelompok Islam". ${ }^{12}$ Endang Saifuddin Anshari yang menempatkan Mohammad Hatta ke dalam kelompok Nasionalis muslim "sekular", yang

\footnotetext{
${ }^{7}$ Sri Edi Swasono, "Religiusitas Pemikiran Ekonomi Mohammad Hatta" dalam Anwar Abbas, Bung Hatta dan Ekonomi Islam (Jakarta: LP3M STIE Ahmad Dahlan, 2008), xix.

${ }^{8}$ Nurcholish Madjid, "Hatta Tipe "Problem Solver"," dalam Mohammad Hatta, Demokrasi Kita (Jakarta: Balai Pustaka, 2004), xlvi-xlviii.

${ }^{9}$ Deliar Noer, Mohammad Hatta Hati Nurani Bangsa, 89.

${ }^{10}$ Mohammad Hatta, Sekitar Proklamasi (Djakarta: Penerbit Tintamas, 1970), 69.

${ }^{11}$ Sri Edi Swasono, "Religiusitas", xix

${ }^{12}$ Bahtiar Effendi, Islam dan Negara, Transformasi Pemikiran dan Praktik Politik Islam di Indonesia (Jakarta: Paramadina, Cetakan I, 1998), 85.
} 
berbeda dengan kelompok nasionalis islami. ${ }^{13}$ Istilah "sekular" di sini tidaklah menunjukkan bahwa tokoh yang masuk kategori ini sebagai orang yang tanpa ikatan apapun dengan agama. Melainkan sebagai pembeda dengan kaum “islami” yang menginginkan negara diatur dengan dasar-dasar agama Islam. Sebaliknya kaum nasionalis "sekular" berpegang pada prinsip pemisahan antara agama dan negara. Ahmad Syafi'i Ma'arif menggugat penyematan Mohammad Hatta sebagai sekular, karena Mohammad Hatta adalah seorang muslim yang taat dalam kata dan laku serta memiliki integritas yang sulit dicari bandingnya. ${ }^{14}$ Mohammad Hatta juga "Negarawan moralis yang paling dihormati di Indonesia". ${ }^{15}$

Menantu Hatta, Sri Edi Swasono, menegaskan bahwa pandangan Pancasila Mohammad Hatta sangat islami. ${ }^{16}$ Kemerdekaan yang diperoleh bangsa Indonesia merupakan rahmat dan kurnia Allah. Indonesia tidak akan merdeka jika kemerdekaan itu tidak diberkati Tuhan. Pengakuan di muka Tuhan ini menyebabkan Pancasila tidak mudah diabaikan. Jika diperhatikan betul-betul, Pancasila ini terdiri atas dua fundamen: pertama, fundamen moral berupa Ketuhanan yang Maha Esa. Kedua, fundamen politik berupa perikemanusiaan, persatuan Indonesia, demokrasi, dan keadilan sosial. Dasar moral berupa Ketuhanan yang Maha Esa memberikan dasar yang kokoh bagi penyelenggaraan negara. Dasar Ketuhanan yang Maha Esa memimpin cita-cita kenegaraan Indonesia untuk menyelenggarakan segala yang baik bagi rakyat dan masyarakat. ${ }^{17}$ Sila Ketuhanan Yang Maha Esa menjadi dasar yang memimpin sila-sila yang lain. Keberadaan Sila Ketuhanan Yang Maha Esa sebagai sila pertama menyebabkan kelima sila saling ikat-mengikat dan menimbulkan pasangan yang harmonis antara kelima sila dalam Pancasila. ${ }^{18}$

George Mc Turner Kahin menjelaskan bahwa Mohammad Hatta "Tidak pernah meninggalkan keyakinannya bahwa Islam dapat memainkan peranan sosio-ekonomis yang progresif, yang membawa Indonesia kepada keadilan sosial yang lebih besar."19 Saat demokrasi mengalami krisis setelah Soekarno menerapkan Demokrasi Terpimpin, Mohammad

\footnotetext{
${ }^{13}$ Endang Saifuddin Anshari, Piagam Jakarta 22 Juni 1945 Sebuah Konsensus Nasional (Jakarta: Gema Insani Press, 1997), 42.

${ }^{14}$ Ahmad Syafi'i Ma'arif, Islam dalam Bingkai Keindonesiaan dan Kebangsaan: Sebuah Refleksi Sejarah (Bandung: Mizan, Edisi Kedua Cetakan I, 2015), 24.

${ }^{15}$ Ahmad Syafi'i Ma'arif, Islam dan Masalah Kenegaraan (Jakarta: LP3ES, 1985), 153.

${ }^{16}$ Sri Edi Swasono, "Religiusitas", xix

17 Hatta, Demokrasi Kita, 38-39.

${ }^{18}$ Mohammad Hatta, Pengertian Pancasila (Jakarta: Idayu Press, 1977), 29.

${ }^{19}$ George Mc Turner Kahin, "Mohammad Hatta Sebagai Pemikir Bebas" dalam penyunting Meutia Farida Swasono, Bung Hatta: Pribadinya Dalam Kenangan (Jakarta:Penerbit Sinar harapan, Universitas Indonesia, 1980), 459.
} 


\section{Ahmad Syauqi Fuady}

Hatta menguraikan bahwa nilai-nilai ajaran Islam yang menuntut kebenaran dan keadilan Ilahi dalam masyarakat serta persaudaraan antara manusia sebagai makhluk Tuhan adalah salah satu dari tiga sumber utama yang menghidupkan cita-cita demokrasi Indonesia. ${ }^{20}$ Dengan alasan itulah Mohammad Hatta yakin bahwa Demokrasi Indonesia tidak akan bisa lenyap dari bumi Indonesia.

Menyadari fakta demografis bahwa mayoritas penduduk Indonesia adalah memeluk agama Islam ${ }^{21}$, Mohammad Hatta berpendapat bahwa menyempurnakan didikan agama Islam adalah suatu hal yang sangat penting dalam memperkuat dan memperkokoh kedudukan masyarakat. Negara Indonesia akan menjadi kuat jika persaudaraan dan tolong-menolong menjadi cita-cita bersama masyarakat. Agama Islam adalah pelita yang sebaik-baiknya dalam memberikan pencerahan rakyat ke dalam masyarakat persaudaraan dan tolong-menolong. ${ }^{22}$ Oleh karena itu pendidikan Islam haruslah menjadi salah satu bagian penting untuk diperhatikan.

Keyakinan positif Mohammad Hatta terhadap agama dinyatakan dengan tegas bahwa bagi Hatta, "Agama adalah salah satu tiang daripada kebudajaan bangsa."23 Kebudayaan diistilahkan oleh Hatta dengan Kultur. Kebudayaan atau kultur adalah "Buah perbuatan manusia, jang merombak dan membentuk alam sebagaimana adanja itu mendjadi penghidupan jang lebih tinggi. ${ }^{24}$ Kebudayaan senantiasa berkembang mengikuti masa yang terus-menerus berubah. Oleh karena itu, suatu masyarakat jika berkeinginan untuk dapat terus hidup, maka hendaklah masyarakat suatu bangsa berusaha untuk terus-menerus memperkembangkan kebudayaannya sesuai dengan akar rumpunnya sendiri. ${ }^{25}$ Kultur, sebagai hasil ciptaan manusia, menganut faham bahwa hasil ciptaan yang lebih sempurna menurut pandangan masa dan tempat akan mengalahkan yang lama. Kultur yang lama akan disingkirkan oleh yang baru, terlebih jika kultur yang lama tidak berdiri di atas akar yang kokoh dan kuat. Kultur suatu

\footnotetext{
${ }^{20}$ Mohammad Hatta, Demokrasi Kita, 30.

${ }^{21}$ Sensus penduduk tahun 2000 mencatat pengikut Hindu $3.651 .939(1,81 \%)$, Budha 1.694 .682 (0,84\%), Muslim 177.528.772 (88,22\%), Kristen dan Katolik 17.954.977 (8,92\%) lihat Ma'arif, Islam dalam Bingkai Keindonesiaan dan Kemanusiaan, 62.

${ }^{22}$ Mohammad Hatta, "Sifat Sekolah Tinggi Islam" dalam Mohammad Hatta, Kumpulan Karangan IV (Jakarta: Penerbitan dan Balai Buku Indonesia, 1954), 107.

${ }^{23}$ Ibid.

24 Mohammad Hatta, "Kemana Arah Kebudajaan Kita?" dalam Mohammad Hatta, Kumpulan Karangan IV (Jakarta: Penerbitan dan Balai Buku Indonesia, 1954), 87.

${ }^{25}$ Ibid.
} 
bangsa yang tidak berdiri di atas akar yang kuat akan cepat sekali mengalami perubahan kulturnya. ${ }^{26}$

Kebudayaan atau kultur, menurut Hatta, memiliki dua bentuk yang berbeda yakni sivilisasi dan peradaban. Kultur menjadi sivilisasi, apabila tujuan jasmani untuk mencapai kesempurnaan hidup yang lebih besar bertitik-berat pada materialisme. Sedangkan kultur lebih merupakan peradaban, apabila faktor-faktor adab dan moral, sebagai ciptaan agama, besar pengaruhnya. Pada peradaban pengaruh tujuan rohani lebih besar dalam mencapai kesenangan hidup. ${ }^{27}$ Kebudayaan yang berwujud peradaban dengan berpedomankan nilai-nilai rohaniah agama, moral, dan adab adalah cita-cita Hatta. Di atas fundamen agama, ilmu pengetahuan, teknik, seni diharapkan Mohammad Hatta dapat tumbuh subur dalam tanah kebudayaan Indonesia. Islam diyakini Mohammad Hatta dapat memenuhi tugasnya sebagai fundamen dasar kebudayaan Indonesia. Sebab Islam senantiasa menuntun umatnya untuk selalu berada di jalan kebenaran, keadilan, serta senantiasa mencari ilmu pengetahuan seluas-luasnya. ${ }^{28}$

Beberapa contoh di atas menegaskan tentang gagasan dan pandangan Mohammad Hatta berkaitan dengan relasi antara agama dan hal politik kemasyarakatan. Nampak kental sekali pandangan Mohammad Hatta yang menajdikan agama sebagai landasan teologis dan filosofis dalam bangunan gagasannya. Jalannya kehidupan sosial politik kemasyarakatan tidaklah bisa dilepaskan dari nilai-nilai agama. Nilai-nilai agama dapat menjadi pondasi dan sumber ajaran dalam menjalankan tata kehidupan kenegaraan dan kemasyarakatan. Pandangan keagamaan Mohammad Hatta lebih bernilai substantif dengan menekankan nilai-nilai baik dari suatu agama ketimbang menampilkan agama dalam bentuk formalisme simbolik.

\section{PEMIKIRAN PENDIDIKAN MOHAMMAD HATTA}

Spektrum pemikiran Mohhamad Hatta sangatlah luas. Hatta dikenal sebagai pemikir yang prolifik untuk persoalan ekonomi, filsafat, politik, sosial-kemasyarakatan, ideologi, agama, dan pendidikan. Khusus untuk pendidikan, kiranya tidak berlebihan jika menempatkan Mohammad Hatta sebagai salah satu tokoh pendidikan Indonesia. Rekam jejak perjuangan organisasinya, buah pikirannya yang terserak dalam berbagai karya tulisannya setidaknya menjadi argumen pendukung pendapat tersebut. Sehingga menarik untuk menelaah buah

\footnotetext{
${ }^{26}$ Mohammad Hatta," Kebudajaan" dalam Mohammad Hatta, Kumpulan Karangan IV (Jakarta: Penerbitan dan Balai Buku Indonesia, 1954), 82.

${ }^{27}$ Ibid.

${ }^{28}$ Yamamoto Haruki, Gelora Menuju Indonesia Baru (Jakarta: Dian Rakyat, 2010), 125.
} 


\section{Ahmad Syauqi Fuady}

pikiran Mohammad Hatta berkaitan dengan topik pendidikan. Uraian berikut ini mencoba menggambarkan sedikit dari gagasan pendidikan Mohammad Hatta.

Pertama, pendidikan yang berlaku di Indonesia merdeka haruslah sesuai dengan kebutuhan dan perkembangan masyarakat dan bangsa sendiri. Mohammad Hatta memberikan catatan kritis terhadap sistem pendidikan pada zaman Belanda. Sistem penidikan zaman Belanda bercorak "utiliteitsonderwijs", yaitu pelajaran yang diberikan di sekolah Belanda hanya untuk memenuhi kebutuhan administrasi pemerintahan dan perusahaan penguasa Belanda. ${ }^{29}$ Dengan sistem pendidikan yang demikian, meski kualitas pengajarannya tinggi, namun hanya anak-anak dengan jumlah yang sangat terbatas dapat mengenyam pendidikan.

Pendidikan yang berlaku di Indonesia, baik yang diselenggarakan oleh pemerintah maupun swasta, harus membuka akses yang seluas-luasnya kepada seluaruh anggota masyarakat. Pendidikan yang berlaku hendaknya memperhatikan bakat dan potensi murid agar mampu diarahkan ke arah jurusan yang dibutuhkan dalam pembangunan masyarakat. Di sisi lain, pendidikan pada dasarnya adalah menyiapkan calon pemimpin bagi masa depan bangsa dan negara. Oleh karena itu tugas pendidikan yang tak kalah penting adalah menumbuhkan rasa tanggung jawab, percaya diri, mempertinggi moral-akhlak, serta memperkuat morilsemangat. $^{30}$

Kedua, sistem pendidikan yang dijalankan di Indonesia haruslah mengutamakan "pendidikan" bukan "pengajaran". Pendidikan harus menjadi pemimpin bagi pengajaran. Pendidikan mengutamakan pembentukan karakter, sedangkan pengajaran memberikan ilmu pengetahuan yang dapat digunakan dengan sebaik-baiknya oleh orang yang memiliki karakter. ${ }^{31}$ Kendati demikian, meski karakter lebih diutamakan daripada pengetahuan, pengetahuan yang mendalam menjadi sendi kepada karakter yang dibentuk dan terbentuk. ${ }^{32}$

Begitu pentingnya karakter, Mohammad Hatta menekankan bahwa "Orang yang mempunyai karakter mudah mencapai kepintaran. Tetapi kepintaran saja tidak dapat

\footnotetext{
${ }^{29}$ Mohammad Hatta, "Perguruan Nasional" dalam Mohammad Hatta, Kumpulan Karangan IV (Jakarta: Penerbitan dan Balai Buku Indonesia, 1954), 125.

${ }^{30}$ Ibid., 126.

${ }^{31}$ Mohammad Hatta, "Soal Pengajaran" dalam Mohammad Hatta, Kumpulan Karangan IV (Jakarta: Penerbitan dan Balai Buku Indonesia, 1954), 100.

32 Mohammad Hatta, "Pendidikan Perwira" dalam Mohammad Hatta, Kumpulan Karangan IV (Jakarta: Penerbitan dan Balai Buku Indonesia, 1954), 118.
} 
membangun karakter yang tak ada pada seseorang." 33 Kemudian, lanjut Hatta, "Kecerdasan dapat dicapai dengan jalan studi oleh orang yang mempunyai karakter. Karena karakter itu pulalah ilmu dapat berjalan terus. ${ }^{\text {34 }}$ Kecerdasan tidak akan mampu memberikan manfaat dan kemajuan bagi masyarakat, jika tanpa dibarengi oleh karakter yang kokoh dan teguh. Kesungguhan, disiplin, tanggung jawab, rajin, dan penuh dedikasi adalah di antara bentuk karakter utama yang mampu menjadi pondasi dasar bagi berkembangnya ilmu pengetahuan.

Lebih dari itu semua pendidikan karakter berarti kita menginginkan peserta didik kita mampu menilai apa yang benar, sangat peduli tentang apa yang benar, dan kemudian melakukan apa yang mereka yakini benar. ${ }^{35}$ Prinsip ini sesuai dan sejalan dengan misi suci ilmu pengetahuan, yakni mencintai kebenaran, mencari kebenaran, dan membela kebenaran yang diyakini. Tanpa kebenaran yang dijadikan pegangan dan prinsip, maka ilmu pengetahuan kehilangan elan vitalnya. Pendidikan dan karakter adalah dua hal yang tidak dapat dipisahkan. Karakter adalah esensi dari pendidikan. Bukanlah suatu pendidikan jika karakter tidak menjadi tujuan utamanya.

Pendidikan karakter hendaknya menjadi perhatian semua pihak yang terlibat dalam pendidikan baik pendidikan formal, informal, dan non-formal. Sejak pendidikan usia dini hingga perguruan tinggi, persoalan tentang karakter ini tidaklah boleh diabaikan. Termasuk juga bagi orang tua untuk selalu memperhatikan karakter anak lewat didikan di rumah.

Ketiga, Mohammad Hatta memberi perhatian yang khusus dan besar akan lahirnya sosok ulama, sebab keberadaan ulama sangat penting dalam bertumbuh dan berkembangnya ajaran Islam. Sayangnya tiap kurun masa, jumlah ulama yang layak dijadikan panutan dan tuntunan semakin menurun. Dunia Islam senantiasa kekurangan sosok ulama besar, termasuk juga Indonesia. Oleh sebab itu, di Indonesia haruslah diselenggarakan pendidikan yang tujuan utamanya adalah mencetak kader-kader ulama yang mampu merespon perkembangan masyarakat yang dinamis.

Sosok ulama yang ideal bagi Hatta adalah sosok ulama yang memiliki perasaan keagamaan dalam dirinya, memiliki pengetahuan keagamaan mendalam, berpandangan yang luas, serta memiliki gerak yang dinamis. Ulama yang memiliki kriteria tersebut yang akan

\footnotetext{
${ }^{33}$ Mohammad Hatta, "Karakter” dalam Kumpulan Karangan IV (Jakarta: Penerbitan dan Balai Buku Indonesia, 1954), 61.

${ }^{34}$ Ibid., 63.

${ }^{35}$ Thomas Lickona, Educating for Character, (Jakarta: Bumi Aksara, 2013), 81.
} 


\section{Ahmad Syauqi Fuady}

mampu menuntun dan membimbing masyarakat menuju kemajuan dan kesejahteraan. Para ulama ini tidak hanya terbatas untuk mengurusi persoalan keagamaan semata, mereka haruslah terlibat dalam urusan negara. Karena jika ulama tidak memikirkan persoalan negara, maka bisa jadi akan ada produk pemerintah yang dapat merugikan bagi perkembangan masyarakat Islam.

Cita-cita yang demikian itu hanyalah mungkin dapat terwujud oleh suatu pendidikan tinggi yang mengajarakan agama dan $i \mathrm{lmu}^{36}$ secara bersama. Pengajaran agama memperdalam perasaan agama, sedangkan ilmu pengetahuan memperluas pemandangan. Oleh sebab itu, pendidikan tinggi yang bertujuan membentuk ulama tidak cukup mengajarakan al-Quran, Hadits, dan hukum Islam saja, melainkan harus ditambah dengan pengetahuan filsafat, sosiologi, sejarah, dan hukum negara. ${ }^{37}$

Keempat, pendidikan harus mampu menempatkan secara seimbang antara teori dan praktik. Teori tidak boleh menegasikan praktik, sebaliknya praktik tidak mungkin mengacuhkan teori. Tidak ada pertentangan antara teori dan praktik. Teori tanpa praktik seumpama pohon yang mati, sedangkan praktik tanpa teori seperti kapal yang tak punya haluan. Teori menjelaskan duduk perkara kausalitas sebab-akibat atas suatu fenomena praktikal. Praktik berarti menggunakan pengetahuan teori dalam menempuh upaya bagi perbaikan. Teori memberi keterangan kepada praktik, sementara praktik memberikan alat dan data baru guna penyempurnaan teori. Praktik menampak karena teori, teori menjadi berisi karena praktik. ${ }^{38}$ Pendidikan yang baik mampu mengajarkan amal (praktik) yang ilmiah (teoritik) sekaligus ilmu (teori) yang amaliah (praktikal).

Beberapa poin di atas menggambarkan setidaknya gaagsan dan pemikiran Mohammad Hatta tentang pendidikan selaras dengan kandungan pokok pendidikan Islam yang meliputi pendidikan tauhid atau keimanan, akhlak atau moral, ilmiah atau teori, amaliah atau praktik, dan sosial kemasyarakatan. ${ }^{39}$

\footnotetext{
${ }^{36}$ Hatta menilai bahwa antara agama dan ilmu tidak saling bertentangan dan bisa berjalan beriirngan. Agama dan ilmu dapat menjadi suluh pelita bagi manusia dalam menjalani hidupAgama dan ilmu memiliki wilayah dan metodenya sendiri. Agama bertolak dari percaya, sebaliknya ilmu bertolak dari ragu-ragu atau tidak percaya. Lihat Mohammad Hatta, Pengantar Ke Djalan Ilmu dan Pengetahuan (Jakarta: P.T. Pembangunan Djakarta, Cetakan keempat, 1964), 45-50.

${ }^{37}$ Mohammad Hatta, "Sifat Sekolah Tinggi Islam", 108-110.

${ }^{38}$ Mohammad Hatta, "Teori dan Praktik" dalam Mohammad Hatta, Kumpulan Karangan IV (Jakarta: Penerbitan dan Balai Buku Indonesia, 1954), 203-208

${ }^{39}$ Departemen Agama RI Direktorat Jenderal Kelembagaan Agama Islam, Metodologi Pendidikan Agama Islam Buku Kedua (Jakarta: Departemen Agama RI Tidak Diperjualbelikan, 2002), 34-35.
}

9 AT-TUHFAH : Jurnal Keislaman. Vol. 7 No.1, 2019 


\section{KESIMPULAN}

Islam bagi Hatta menjadi prinsip dasar hidup dan sumber gagasan dalam aktivisme dan peran kepemimpinannya. Islam tidak hanya terbatas sebagai nilai-nilai pribadi saja, namun juga sebagai sumber nilai bagi pelaksanaan kehidupan bernegara dan bermasyarakat. Nila-nilai Islam lebih utama dibandingkan formalisme simbolik. Menurut Hatta meski Indonesia bukan negara agama, nilai-nilai Islam dapat diperjuangkan secara legal konstitusional lewat lembaga legislatif. Bagi Mohammad Hatta nilai-nilai ketuhanan menjadi fundamen moral agar jalannya pemerintahan tidak menyimpang dari tujuan. Hatta berkeyakinan Islam dapat memainkan peran signifikan dalam kehidupan sosial kemasyarakatan di Indonesia. Nilai-nilai Islam berupa persaudaraan, tolong-menolong, keadilan menjadi sumber bagi demokrasi Indonesia. Islam diyakini Hatta dapat memperkokoh kebudayaan Indonesia agar menjadi perdaban yang kokoh.

Pendidikan telah menjadi tema yang digeluti Mohammad Hatta sejak sebelum Indonesia merdeka. Partai yang didirikan Mohammad Hatta dinamai Pendidikan Nasional Indonesia (PNI-Baru) yang orientasi utamanya adalah menjadi partai kader yang mendidik para anggotanya untuk memiliki kesadaran dan tanggung jawab sebagai pemimpin. Setelah Indonesia merdeka, pendidikan tetap menjadi perhatian utama Mohammad Hatta. Pendidikan (human investment) baginya adalah investasi penting dalam pengembangan sumber daya manusia bagi kemajuan bangsa dan negara. Gagasan dan pemikiran pendidikan Mohammad Hatta memiliki keselarasan dengan kandungan pendidikan Islam yakni pendidikan keimanan, keilmuan, akhlak, amal praktik, dan sosial.

\section{DAFTAR PUSTAKA}

Abbas, Anwar. 2008. Bung Hatta dan Ekonomi Islam. Jakarta: LP3M STIE Ahmad Dahlan.

Anshari, Endang Saifuddin. 1997. Piagam Jakarta 22 Juni 1945 Sebuah Konsensus Nasional. Jakarta: Gema Insani Press.

Departemen Agama RI Direktorat Jenderal Kelembagaan Agama Islam. 2002. Metodologi Pendidikan Agama Islam Buku Kedua. Jakarta: Departemen Agama RI Tidak Diperjualbelikan.

Effendi, Bahtiar. 1998. Islam dan Negara, Transformasi Pemikiran dan Praktik Politik Islam di Indonesia. Jakarta: Paramadina, Cetakan I.

Haruki, Yamamoto. 2010. Gelora Menuju Indonesia Baru. Jakarta: Dian Rakyat.

Hatta, Mohammad. 2004. Demokrasi Kita. Jakarta: Balai Pustaka. 1953. Kumpulan Karangan I. Jakarta: Penerbitan dan Balai Buku Indonesia. 1954. Kumpulan Karangan IV. Jakarta: Penerbitan dan Balai Buku Indonesia. 1964. Pengantar Ke Djalan Ilmu dan Pengetahuan. Jakarta: P.T. Pembangunan Djakarta, Cetakan keempat. 


\section{Ahmad Syauqi Fuady}

. 1977. Pengertian Pancasila. Jakarta: Idayu Press.

. 1970. Sekitar Proklamasi. Djakarta: Penerbit Tintamas.

. 2013. Untuk Negeriku Sebuah Otobiografi Vol. 1: Bukittinggi-Rotterdam Lewat Betawi. Jakarta: Kompas, cetakan ketiga, September.

Kahin, George Mc Turner. "Mohammad Hatta Sebagai Pemikir Bebas" dalam penyunting Meutia Farida Swasono. 1980. Bung Hatta: Pribadinya Dalam Kenangan. Jakarta:Penerbit Sinar harapan, Universitas Indonesia.

Lickona, Thomas. Educating for Character. Jakarta: Bumi Aksara.

Ma'arif, Ahmad Syafi'i. 2015. Islam dalam Bingkai Keindonesiaan dan Kebangsaan: Sebuah Refleksi Sejarah. Bandung: Mizan, Edisi Kedua Cetakan I. Ahmad Syafi'i. 1985. Islam dan Masalah Kenegaraan. Jakarta: LP3ES.

Noer, Deliar. 1982. Gerakan Moderen Islam di Indonesia 1900-1942. Jakarta: LP3ES, cetakan kedua.

Noer, Deliar. 2012. Mohammad Hatta Hati Nurani Bangsa. Jakarta: Kompas. 